\title{
Monteverdi e a Invenção de um Estilo: Sobre a Composição do Combattimento di Tancredi e Clorinda e a Definição do Stile Concitato
}

\author{
Susana Cecília Igayara
}

\section{Introdução}

O Esteta italiano Enrico Fubini, em seu capítulo sobre a música na cultura iluminista, considera que todas as polêmicas surgidas sobre a música nos séculos XVII e XVIII estão relacionadas a dois acontecimentos revolucionários: a invenção da harmonia e a invenção do melodrama. Estes dois acontecimentos nascem juntos, uma vez que a preferência pela monodia, em oposição à polifonia, requer necessariamente um acompanhamento musical que permita e favoreça uma sucessão temporal dos diálogos e da ação dramática ${ }^{1}$.

Claudio Monteverdi, nascido em Cremona em 1567 e morto em Veneza em 1643, foi um compositor fundamental no processo de passagem da estética renascentista para a estética barroca, e na análise de sua trajetória a discussão sobre as questões apontadas por Enrico Fubini são primordiais.

Monteverdi começa sua carreira como compositor de madrigais, gênero polifônico que espelha a cultura musical da renascença, e assina suas primeiras publicações como aluno de Marco Antonio Ingegneri, compositor conceituado no gênero. A adoção das inovações trazidas pelo melodrama não significam, na obra de Monteverdi, um abandono da polifonia. O compositor defenderá a manutenção das duas práticas, tratando-se de estilos diferentes para situações distintas. 
Entre 1587 e 1638, Monteverdi edita sua música, que vai ao longo do tempo sofrendo transformações substanciais, sob o mesmo título de Livros de Madrigais. É no VIII Livro de Madrigais, publicado em 1638, que se encontra editado o Combattimento di Tancredi e Clorinda, já apresentado ao público em 1624. O conteúdo de seus Livros de Madrigais ultrapassa, e muito, a caracterização do título, e aí são encontradas propostas estéticas audaciosas e revolucionárias, alvo de repetidas polêmicas, seguidamente respondidas, no todo ou em parte, pelos prefácios dos livros seguintes. A adoção do baixo contínuo, a partir do VII Livro, e a invenção do estilo concitato, no VIII Livro, são inovações significativas que apontam em direção a uma nova proposta composicional, uma nova concepção musical. O Combattimento é incluído no VIII Livro como um opúsculo, que deveria ser apresentado seguido de outros madrigais senza gesto.

O Combattimento pode ser visto como um importante ponto de interesse na produção monteverdiana, que em sua vida longeva apresentou sempre um componente de transformação, experimentação e invenção em sua personalidade criativa como compositor.

\section{Trajetória de Monteverdi Rumo a Veneza}

A trajetória de Claudio Monteverdi pode ser dividida em três grandes períodos, correspondendo aos locais onde fixou residência: Cremona, Mântua e Veneza.

O primeiro registro que se tem de Monteverdi é o de Batismo, em Cremona, cidade natal onde iniciou os estudos e onde publicou as primeiras obras. Além do contato com o professor Marco Antonio Ingegneri, pode ser citada sua atuação como cantor de coro, desde a infância, e como violista. São estas as funções que ocupará em seu primeiro emprego, na corte de Mântua, onde terá contato com outra importante influência: o também madrigalista Giaches de Wert, holandês, que morreria em 1596. O III Livro de Madrigais, de 1592, já é dedicado ao Duque Vincenzo I de Gonzaga, filho e sucessor de Guglielmo e Leonora de Áustria, a quem Monteverdi estará ligado durante toda sua estada em Mântua. A partir de 1600 tornar-se-á Mestre de Música de Sua Alteza Sereníssima, e neste posto permanecerá até 1612, quando seria dispen- 


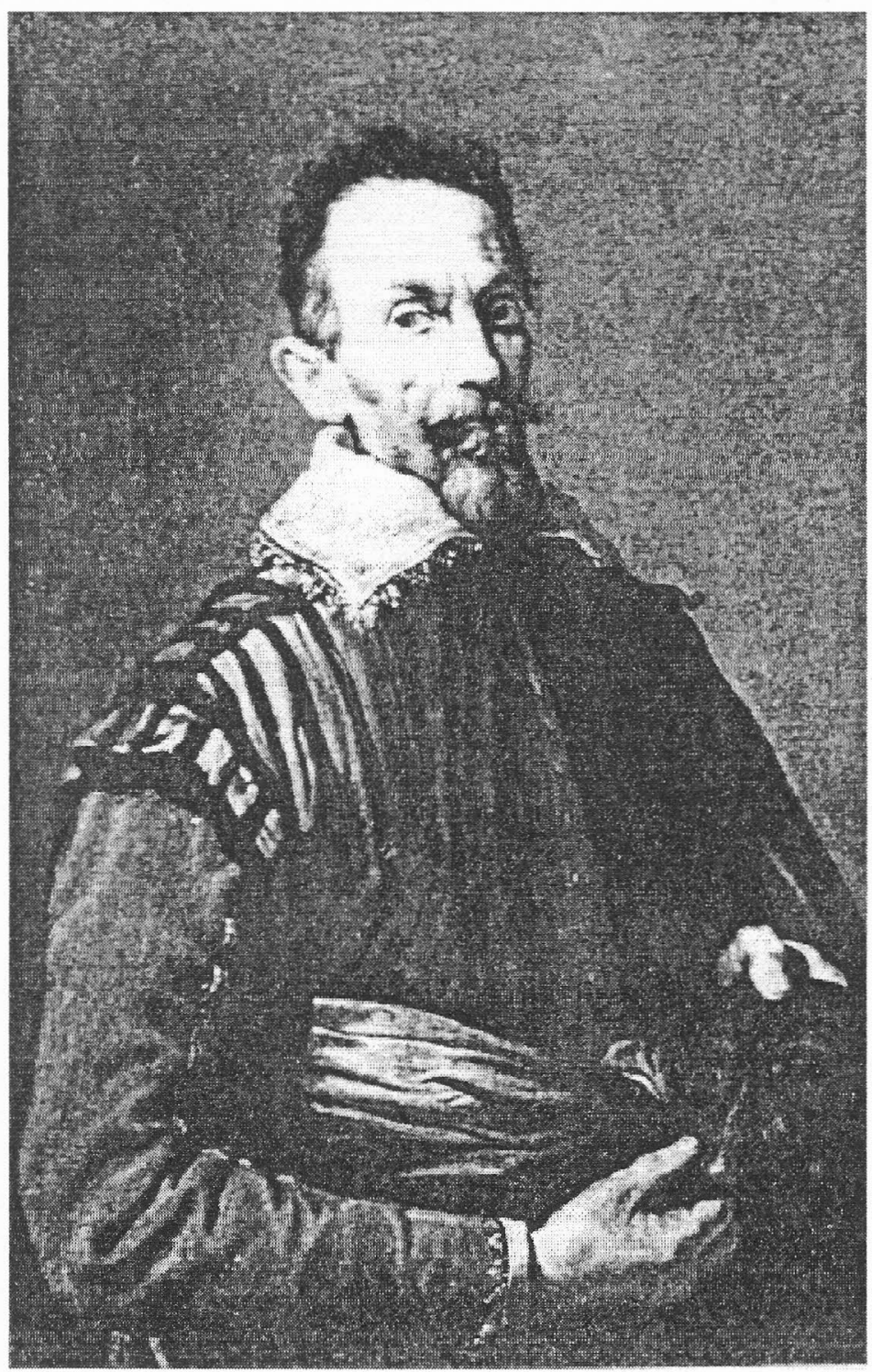


sado dos serviços da Corte, após a morte de Vincenzo I. Suas primeiras incursões no terreno da música dramática estão ligadas à corte dos Gonzaga e às novidades trazidas de Florença. Orfeo, de 1607, foi representado no Carnaval, para um público restrito da Accademia degli Invaghiti. Este tipo de manifestação musical era então uma novidade no ambiente artístico de Mântua, atento às proposições da Camerata Fiorentina, da qual surgiram as primeiras óperas ${ }^{2}$. Em 1608 Monteverdi já apresentava uma nova Ópera: Arianna, da qual restou apenas o célebre Lamento.

A saída de Monteverdi da Corte de Mântua não significou um rompimento. O compositor continuará a compor por encomenda para esta e para outras cortes italianas. Antes de transferir-se para Veneza, o compositor visitou Milão e Ferrara. Não encontrando um posto nestas cidades, voltou a Cremona, onde passou um ano, até que se candidatasse para o cargo de Mestre Capela da Igreja de San Marco, em Veneza, vago com a morte do Padre Martinengo.

A escolha foi deliberada por sufrágio, tendo como eleitores os Procuradores de Veneza. Após passarem por exame diversos outros compositores, indicados por todos os reitores em terra-firme, assim como os residentes das Senhorias de Milão e Mântua, Monteverdi foi considerado o compositor mais preparado para o cargo. Foi oferecido a ele um salário de 300 ducados anuais, o que constituía uma significativa melhora em relação ao seu salário anterior na Corte de Mântua, então de 200 ducados anuais.

A mudança para Veneza, no entanto, não significou apenas uma melhoria em seus ganhos, mas também um alargamento de sua prática musical, sobretudo como compositor. A sociedade veneziana, tradicionalmente ligada ao comércio e à navegação marítima, passava nesse momento por transformações em sua atividade econômica. Alguns fatos ilustram este momento de crise da atividade comercial veneziana: a perda de Chipre, em 1570; a presença dos ingleses e holandeses no mediterrâneo, combinando comércio e pirataria, a partir de 1580; a expansão

2. A Camerata Fiorentina reunia um grupo de músicos e intelectuais que buscavam no drama grego a inspiração para uma renovação musical, baseados no princípio do Recitar cantando, opondo-se à polifonia e propondo uma música monódica acompanhada, dando maior importância à ação dramática e ao texto, através do recitativo. Liderados pelo Conde Giovanni de Bardi, mentor do grupo, estavam Jacopo Peri, composi- 
do Império Otomano por volta de 1620 , prejudicando as rotas comerciais; a abertura do Atlântico.

Para o historiador Peter Burke, neste período ocorre uma mudança no estilo de vida da elite veneziana, tradicionalmente vista como uma elite incomum para os padrões europeus. Não era uma nobreza afeita à ostentação, e sua frugalidade chegou a ser comparada à avareza, com um estilo marcado pela seriedade e pela prudência. Durante o século XVII, esse tradicional estilo, marcado por uma certa simplicidade pessoal, começa a dar espaço a uma maior ostentação, processo por vezes descrito como uma substituição do estilo espanhol pelo estilo francês. Um viajante e embaixador britânico relata o fato, em 1612, um ano antes da mudança de Monteverdi para Veneza:

Eles aqui mudam as suas maneiras... Seu antigo modo de vida era o comércio; o que está agora totalmente abandonado, pois eles se voltam para a terra comprando casas e terras, equipando-se de carruagem e cavalos, e entregando-se a uma boa vida com mais ostentação e galanteria do que aquela a que estavam acostumados... seu costume era enviar os filhos ao Levante, em galeras, para familiarizá-los com a navegação e o comércio. Agora, enviam-nos em viagens para aprender antes os modos do cavalheiro que os do mercador ${ }^{3}$.

O ambiente que Monteverdi encontra, portanto, é o de uma sociedade que se desloca do mar para a terra, do trabalho para o prazer, consumo e ostentação. Neste panorama, a Ópera era um dos prazeres oferecidos aos cortesãos, e a demanda por espetáculos e pela novidade era cada vez maior. Cabe aqui lembrar que os primeiros Teatros Públicos, com a entrada feita mediante a compra de um ingresso, e não por convite, foram abertos em Veneza, a partir de 1637. No final do século XVII, havia doze Teatros Líricos em Veneza, dos quais oito eram propriedades de famílias nobres. Era comum a representação de seis, oito ou até mais espetáculos simultâneos, tamanha a demanda pela Ópera durante o Carnaval, onde encontravam-se mercadores, diplomatas, políticos, príncipes, oficiais, embaixadores de toda Europa,

tor e autor de Euridice, a primeira ópera concebida ( 1601), Giulio Caccini, cantor e compositor, também autor de uma Euridice, Vincenzo Galilei, pai do astrônomo Galileu Galilei, músico que tocava viola e alaúde e que escreveu o polêmico Dialogo Della Musica Antica e Della Moderna.

3. Citado em Burke, 1991, p. 149. 
divididos entre os espetáculos musicais, os Bailes de Máscaras e o jogo. O Teatro era um ponto de encontro social, uma extensão dos negócios e da diplomacia ${ }^{4}$.

É em Veneza que a produção musical de Claudio Monteverdi atinge seu apogeu, sobretudo com a Ópera. Infelizmente muitas de suas óperas foram perdidas, restando delas apenas o registro das execuções. Em 1624, o Combattimento di Tancredi e Clorinda foi apresentado no Palácio Mocenigo, durante o Carnaval. Neste mesmo palácio seria apresentada uma outra ópera, Proserpina Rapita, em 1630, por ocasião do casamento de sua filha. Mocenigo, citado por Monteverdi como "senhor particular", era um patrício veneziano, membro de uma das mais tradicionais famílias da elite ${ }^{5}$.

O Combattimento di Tancredi e Clorinda é uma obra dramática sem ser uma ópera. Para o regente Nikolaus Harnoncourt, responsável por uma das gravações disponíveis, a partir de Arianna cada obra é um passo em direção às suas últimas óperas, que se constituiriam em seus produtos melhor acabados: Il Ritorno d'Ulisse in Patria (1641) e L'Incoronazzione di Poppea (1642).

O Combattimento poderia ser visto, a partir dessa concepção, como uma obra dramática experimental que caminha para uma maior estruturação da música dramática, o que ocorreria com as últimas óperas.

4. O primeiro Teatro público de Ópera de Veneza foi o San Cassiano, inaugurado em 1637, com a 6́pera Andromeda, do compositor romano Francesco Manelli. Este Teatro manteve sua atividade até 1800 , quando foi destruído. Ainda em vida de Monteverdi, três novos Teatros foram inaugurados: o SS. Giovanni e Paolo em 1638, para o qual Monteverdi compôs Adone; o San Moisè, em 1639, onde foi levada a ópera Arianna, como espetáculo de inauguração; e o Novissimo, em 1641. Nos Teatros de Veneza foram ainda representadas as suas óperas Le Nozze d'Enea e Lavinia (1641) no SS. Giovanni e Paolo; Il Ritorno d' Ulisse in Patria, (1641), no San Cassiano; e L'Incoronazione di Poppea, em 1642, no SS. Giovanni e Paolo. Para um panorama da música em Veneza, ultrapassando o período histórico aqui estudado, consultar Bridgman, Nanie, 1984.

5. Encontra-se também a grafia Mozzenigo, ou ainda Mozenigo, tratando-se da mesma família ou pessoa. 


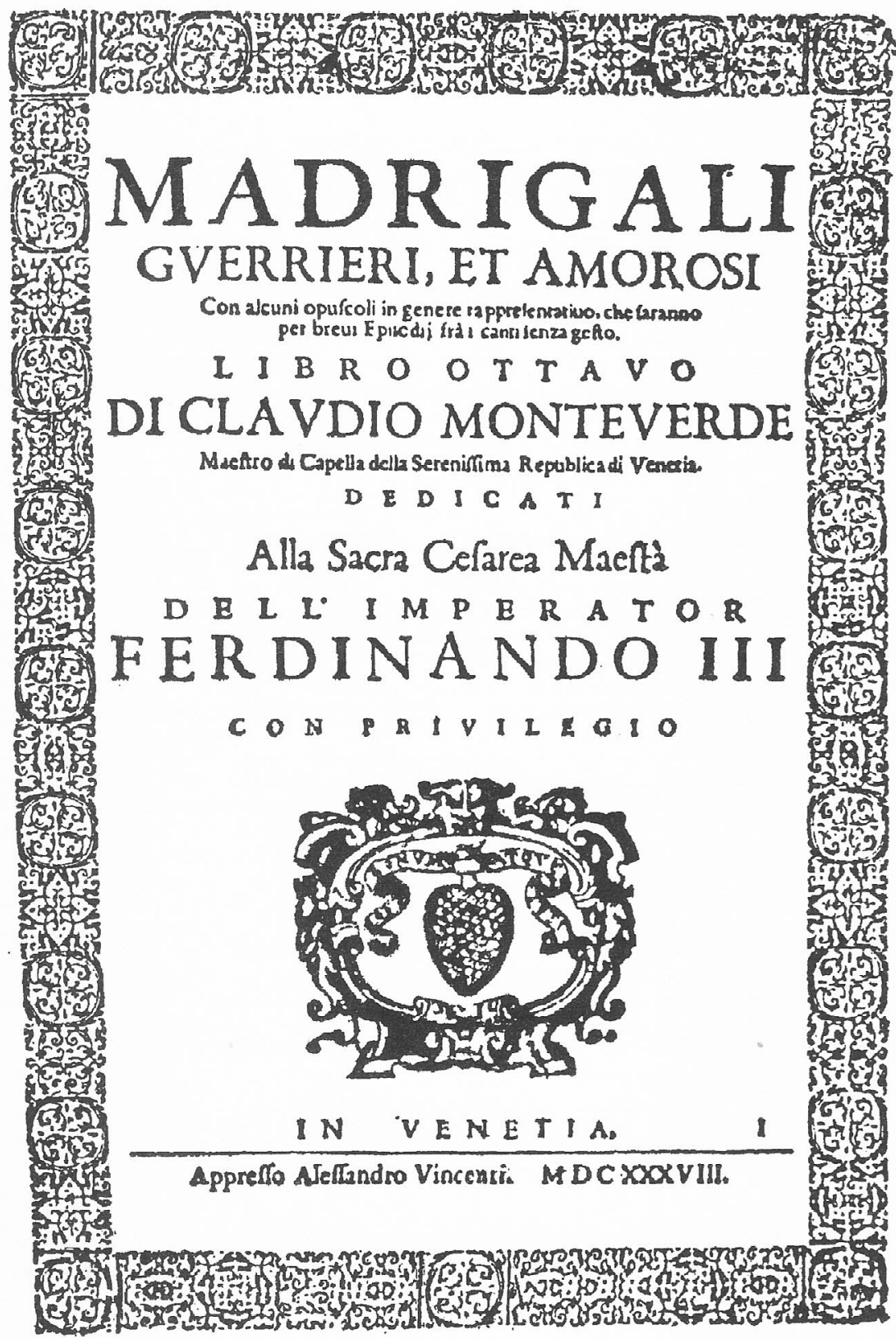




\section{O Combattimento di Tancredi e Clorinda e a Invenção do Estilo Concitato}

O Combattimento di Tancredi e Clorinda foi composto a partir do Canto XII do poema épico Gerusalemme Liberata, de Torquato Tasso, que não foi concebido como obra dramática ${ }^{6}$. A obra de Monteverdi possui um perfil bastante particular, mesclando características narrativas e dramáticas. Embora na época o costume, para as obras dramáticas, fosse o compositor escrever sobre um libreto previamente escolhido, neste caso Monteverdi explica que, após experiências com transformações no tempo musical, a fim de exprimir o sentimento da ira, procurou o texto de Tasso como o mais adequado para expressar as paixões que desejava, o que demonstra uma escolha de texto feita pelo próprio compositor, para servir a um objetivo musical:

[...] ouvi neste pouco exemplo a semelhança do afeto que procurava, ainda que a oração não seguisse com os pés a velocidade do Instrumento, e para chegar a uma prova maior, agarrei-me ao Divino Tasso, como poeta que exprime com tanta propriedade e naturalidade com a sua oração aquelas paixões que quer descrever, e encontrei a descrição que faz do Combate de Tancredi com Clorinda por ter eu as duas paixões contrárias a pôr em canto: Guerra, depois súplica e morte $[\ldots]^{7}$

No prefácio à edição de 1638, Monteverdi apresenta a obra como um "opúsculo em gênero representativo", mesclado a outros madrigais também guerreiros. Utiliza três personagens: Clorinda, Tancredi e o Narrador, apresentado simplesmente como "Il Testo". Um dos primeiros exemplos de recitativo com acompanhamento pleno, utiliza como con-

6. Torquato Tasso (1549-1595) escreveu a Gerusalemme Liberata em 1581, na Corte da família Este de Ferrrara. Em 1593 publicou uma nova versão do poema épico, escrito em oitava rima, com o título de Gerusalemme Conquistata. O poema trata da conquista de Jerusalém aos muçulmanos, episódio histórico da I Cruzada, em 1099. Tasso esteve em Mântua sob proteção de Vincenzo I, após passar por recuperação no Hospital S. Anna, onde havia sido internado para tratamento de um ataque de paranóia. Nessa ocasião conheceu Claudio Monteverdi, que por diversas vezes musicou poemas seus.

7. Claudio Monteverdi - , "A chi Legge” - Prefácio ao VIII Livro de Madrigais Madrigais Guerreiros, em De Paoli, 1973, p. 417. Tradução nossa. O livro organizado por De Paoli reúne os textos de Monteverdi que sobreviveram em forma de dedicatórias, prefácios e cartas. 
junto instrumental quatro violas da brazzo (Soprano, Alto, Tenor e Baixo), Contrabaixo da gamba e Clavicembalo 8 .

O Narrador é o papel preponderante, enfatizando o caráter narrativo e a utilização do recitativo, mas há também utilização de diálogos diretos. As instruções para a execução, tanto para os cantores como para os instrumentistas, são bastante precisas: onde o canto pode ser ornamentado, onde e como os cantores devem movimentar-se, a importância do entendimento do texto do Narrador, cuja voz "deve ser clara, firme e de boa pronúncia". Destaca ainda a importância da manutenção do tempo e a observação das paixões descritas no texto, inclusive pelos instrumentistas, que deverão tocar "em imitação às paixões da oração".

Ainda sobre a execução, Monteverdi explica que a música deverá ser feita de surpresa, cantando-se depois alguns madrigais sem gesto, e que Clorinda deverá estar armada até os pés, e Tancredi armado sobre

8. Para uma melhor compreensão, reproduzimos aqui o texto inicial de Monteverdi, com tradução nossa:

Combate de Tancredi e Clorinda

Palavras do Senhor Torquato Tasso

Combate em Música de Tancredi e Clorinda, descrito por Tasso; o qual querendose que seja feito em gênero representativo, far-se-á de surpresa [alla sprovista] (depois cantando-se alguns Madrigais sem gesto) da parte da Câmara [dos aposentos] da qual se fará a Música. Clorinda armada até os pés, seguida de Tancredi armado sobre um Cavalo Mariano, e o Texto na hora que começará o Canto. Farão os passos e gestos no modo que a oração exprime e nada de mais nem de menos, observando estes cuidadosamente os tempos, golpes e passos, e os instrumentistas os soam incisivos [incitati] e macios [molli], e o Texto pronuncia as palavras 'a tempo', de maneira que a criação venha encontrar-se unida em uma imitação. Clorinda falará quando lhe couber, calando o Texto; e assim Tancredi. Os instrumentos, ou seja, quatro Violas "da brazzo", Soprano, Alto, Tenor e baixo, e contrabaixo "da Gamba" que continuarão com o Clavicembalo, deverão ser tocados em imitação às paixões da oração; a voz do texto deverá ser clara, firme e de boa pronúncia, em pouco separada dos instrumentos para que melhor seja entendida na oração. Não deverá fazer gorgeios [gorghe] nem trilos em outro lugar que não somente no canto da estância que começa com "Notte"; os outros levarão a pronúncia à semelhança das paixões da oração. De tal maneira (há já doze anos) foi representado no Palácio do Ilustríssimo e Excelentíssimo Senhor Girolamo Mozzenigo, meu Senhor particular.

Com toda cortesia, por ser Cavalheiro de boníssimo e delicado gosto; em tempo, contudo, de Carnaval por passatempo de sarau; na presença de toda Nobreza a qual ficou movida pelo afeto de compaixão de tal maneira que estiveram quase a derramar lágrimas; e deram aplauso por ter sido canto de gênero ainda não visto nem ouvido. (De Paoli, 1973). 
um Cavalo Mariano. Os passos e gestos deverão ser feitos como o texto exprime, "nada de mais nem de menos, observando cuidadosamente os tempos, golpes e passos".

A precisão das instruções demonstra o cuidado com o conjunto da obra, ou seja, sua preocupação musical, dramática, cênica, de forma que a não observância de algum desses preceitos significaria uma quebra no conjunto geral da criação. Monteverdi destaca, no final deste texto introdutório, o fato de ter sido, em sua primeira representação, "canto de gênero ainda não visto nem ouvido". O texto é uma perfeita "bula", tal como foram usadas no século XX, no momento em que a escrita tradicional já não era capaz de registrar o efeito imaginado pelo compositor, que então recorria a explicações verbais, grafismos e criação de novos códigos. De maneira semelhante, o texto introdutório de Monteverdi, assim como as indicações de ação dramática que são escritas na partitura, para cantores e instrumentistas, são o recurso possível para a comunicação de novas idéias musicais a músicos acostumados a uma prática antiga. A escrita tradicional já não era suficiente.

A classificação desta peça tem dividido os autores que estudaram a obra de Monteverdi. A adoção do gênero novo é uma das características que tornam a obra tão incomum, e diversos autores apresentam a sua visão desta partitura.

Para Robert Donington, o Combattimento é um exemplo da inventividade e fluidez do início do Barroco, relacionada à Ópera sem ser Ópera. Para este autor, do ponto de vista da mímica, a obra poderia ser descrita como um oratório secular, extremamente poderosa e não usual. Do ponto de vista do Narrador, seria possível descrevê-la como um Ópera miniatura ${ }^{9}$.

Maurice Roche vê no Combattimento o modelo, o protótipo de toda a música dramática da época, pela quantidade de novidades e invenções de todas as ordens, realmente teatrais, além de suas qualidades musicais ${ }^{10}$.

Denis Arnold, autor que se dedicou à obra de Monteverdi e seus contemporâneos em diversos estudos, considera o Combattimento di Tancredi e Clorinda como uma cena dramática.

Gary Tomlinson, que em seu um livro valoriza mais a produção madrigalesca do que a obra dramática, vê na definição do concitato uma

9. Donington, 1981.

10. Roche, 1960, p. 131. 
racionalização de Monteverdi. Ao contrário dos autores que analisam este período do início do Barroco, o autor lê o Combattimento como eco do madrigalismo, através dos efeitos, valorizando mais o conteúdo de mimese do que a ação dramática ${ }^{11}$.

Por outro lado, Paolo Fabbri, em seu extensamente documentado Monteverdi, destaca o caráter híbrido da obra. Considera que o Combattimento se diferencia por sua natureza em primeiro lugar narrativa e fortemente dramática, unindo momentos expositivos, dialogais, de ação, épicos, meditativos e líricos, utilizando para isso mais de uma voz-personagem. $\mathrm{O}$ caráter híbrido da peça aparece na integração de elementos à primeira vista excludentes: uma teatralidade de câmara; a utilização de protagonistas imersos na disputa (Tancredi e Clorinda) e um observador externo (o Narrador); o uso de diálogo direto e ação indireta; a confecção do drama em primeira pessoa e um relato visualizado que não atenua a incandescência ${ }^{12}$.

Para Robert Donington, a chave para a abertura formal do estilo representativo está no próprio recitativo. Para ele, o recitativo não é apenas declamatório, mas aberto na forma e indeterminado em seu tamanho, e permite ao cantor explorar cada mudança de sentimento e cada inflexão verbal. O estilo representativo é "drama em música", não importando se sua destinação é o teatro, a igreja ou a cantata de câmara.

Apesar de opiniões diversas, ou mesmo divergentes, há um acordo no que concerne à importância desta obra no conjunto da produção de Claudio Monteverdi. E esta importância é realçada pelo próprio autor, que valoriza o dado de novidade encontrado e os resultados conseguidos na proposição do concitato, definido por ele mesmo como um novo estilo na arte musical, conseguido a partir da observação dos filósofos e da investigação musical.

A criação do stile concitato, estilo agitado, surge da premissa barroca de que o propósito da música é "mover o espírito". Observando os principais afetos descritos pelos filósofos, em especial Platão, o compositor não teria encontrado correspondente musical para o afeto da Ira, embora houvesse para a Temperança e Humildade ou Súplica. Aplicando os pés métricos usados pelos poetas antigos, procura uma transformação do tempo lento no tempo veloz, e chega à subdivisão do tempo em dezesseis

11. Tomlinson, 1990.

12. Fabri, 1985. 
semicolcheias rebatidas. O procedimento é aplicado tanto aos instrumentos como ao canto, e ambos deveriam ter em mente o fato de estarem com isso expressando os afetos da cólera, da ira. O procedimento, que depois seria largamente usado, causou riso nos instrumentistas, conforme comentário do próprio compositor, em seu prefácio. Ainda nesta obra o compositor cria um novo efeito, depois definitivamente incorporado à composição e execução musicais: o pizzicato nas cordas. Na falta do termo, que seria criado posteriormente, o compositor explica que o arco deveria ser deixado e as cordas puxadas com dois dedos ${ }^{13}$.

A contribuição para o desenvolvimento da música instrumental, apesar de seu trabalho ter girado sempre em torno da música vocal, também é um destaque a ser feito. Anna Amalie Abert, em seu pronunciamento no Congresso de Musicologia dedicado à obra de Monteverdi, em 1967, apontou na invenção do concitato a "decisiva amplificação das possibilidades expressivas musicais, para cuja realização concorria sobretudo a participação do elemento instrumental"'14.

Seria a transposição dos recursos madrigalescos, tão largamente praticados na música vocal, para o âmbito instrumental, justificando-se desta forma a inclusão no VIII Livro de Madrigais? Ou, ao contrário, seria esta obra fruto de um olhar mais diretamente voltado às possibilidades expressivas dos instrumentos, que se encontravam num processo de evolução constante, apontando justamente o caminho inverso, a busca da expressão musical não necessariamente vinculada à palavra, podendo expressar-se por recursos instrumentais próprios, a serem "inventados", descobertos? Acreditamos ser a confluência destas duas possibilidades o que faz a riqueza e o caráter híbrido desta composição.

13. Todas as explicações do autor, aqui reproduzidas, encontram-se na partitura editada por Malipiero. A publicação das obras de Claudio Monteverdi por Gian Francesco Malipiero, ele próprio também compositor, sob o título geral Opera Omnia, em dezesseis volumes, foi um grande empreendimento, que se estendeu de 1926 a 1942, com uma revisão feita em 1954 pela Editora Universal de Viena. A partir de 1970 está sendo publicada uma nova edição, pela Fundação Claudio Monteverdi di Cremona, adotando critérios científicos e rigor filológico desconhecidos por Malipiero, mas tomando por base este trabalho de inestimável importância. Algumas obras desconhecidas à época da edição de Malipiero foram acrescentadas ao corpus monteverdiano, editadas por De Paoli, Osthoff, Kurtzmann, Fabbri.

14. Abert, 1967, p. 212. 
Revista Música, São Paulo, v. 9 e 10, pp. 77-91, 1998-1999 89

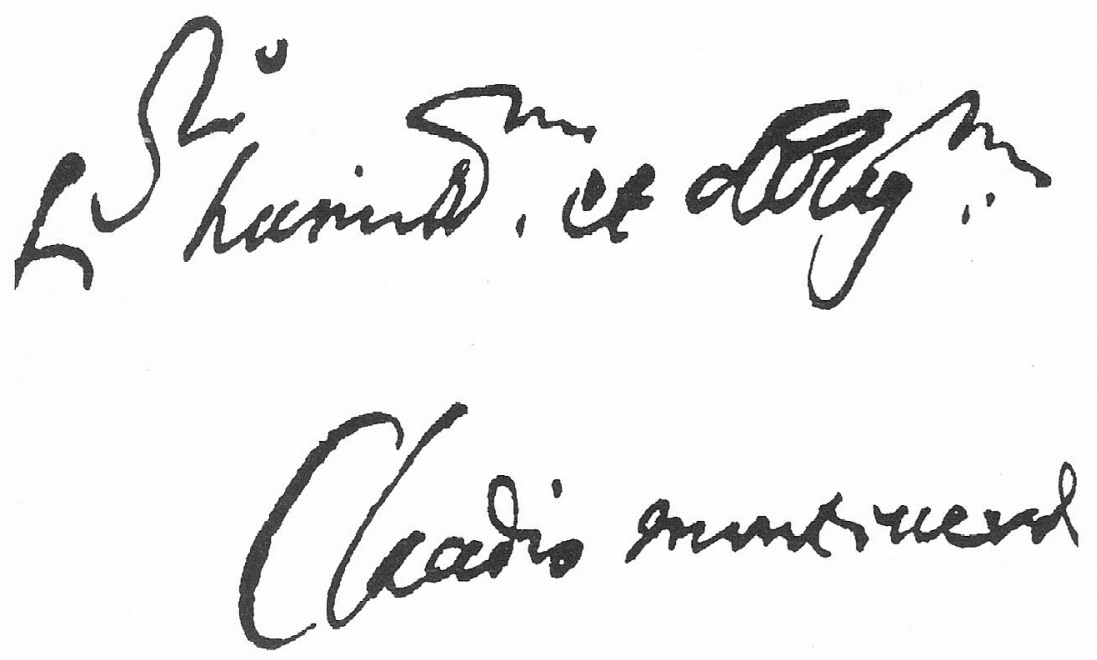


O que gera esses efeitos, qual a razão da introdução de tantos elementos novos, o que faz com que se crie não apenas um efeito rítmico, mas um estilo definido, que seria utilizado em outras ocasiões e por outros autores? Para Claude Palisca, se há um elemento de união na diversidade de manifestações musicais que classificamos como barrocas, este elemento é a crença no dever da música de mover os afetos, e é esta crença que determina o estilo musical. Uma maneira de distinguir uma obra barroca seria questionar se ao elaborar a obra musical a meta dominante do compositor foi a expressão dos afetos ${ }^{15}$.

A teoria dos afetos, em voga do século XVI ao século XVIII, vem da crença proposta por Aristóteles de que existem distintos estados aos quais chamamos medo, amor, ódio, cólera, alegria. Desde o século XVI, o principal objetivo da poesia e da música é o de despertar os afetos. Cumpre distinguir os afetos de emoções, pois a ciência da época via os afetos ou paixões como o resultado de alterações nos fluidos do corpo. As sensações externas e internas estimulariam o mecanismo do corpo para alterar o estado dos fluidos, que se-riam os responsáveis pelos afetos descritos acima. O estudo mais completo realizado no período sobre o funcionamento dos afetos foi o tratado de Descartes, As Paixões da Alma, de 1649. É neste sentido que Monteverdi conclui que a Arte Musical estava incompleta antes da invenção do estilo agitado, pois um dos afetos existentes no homem nunca havia sido expresso musicalmente, e o dever da música seria mover o espírito, e movê-lo através de afetos contrários.

O componente de invenção presente na criação do estilo concitato revela-se através do próprio método de trabalho do compositor. Em seu texto, Monteverdi não se preocupa apenas em justificar a necessidade do novo estilo, esforça-se em clarificar os passos de sua investigação e ressalta que o resultado é fruto de muita labuta. O novo estilo de composição criado é fruto da experimentação, as obras que surgem são a prova da necessidade do novo estilo, desvendando sua atitude diante da composição musical. O paralelo do método de trabalho descrito com o Empirismo de seu contemporâneo Francis Bacon é inevitável. Bacon (1561-1626) propõe uma ciência sustentada pela observação e pela experimentação, que formularia indutivamente as suas leis, partindo da consideração de casos ou eventos particulares para chegar a generalizações. Assim é a

15. Palisca, 1978, p. 16. 
música de Monteverdi: não feita a partir de cânones definidos a priori, mas fruto da investigação constante e consciente e da aplicação dos resultados obtidos em novos trabalhos. Por esta razão ele defende e advoga para si o mérito da criação do novo estilo, e também por esta razão foi alvo tanto de admiração como de grandes polêmicas estéticas.

A partir do panorama exposto, pode-se ler o Prefácio de Claudio Monteverdi ao VIII Livro de Madrigais como um verdadeiro manifesto estético. Tanto o texto como a obra que o motivou, o Combattimento di Tancredi e Clorinda, apresentam as propostas centrais do Barroco, e são um passo decisivo na trajetória que traria a autonomia da música como arte.

\section{Bibliografia}

Abert, Anna Amalie. "Monteverdi e lo sviluppo dell'Opera". Rivista Italiana di Musicologia II, 2. Atti del Convegno di studi dedicato a Claudio Monteverdi. Siena, 28-30 aprile 1967.

ARnold \& Fortune (ed). The Monteverdi Companion. New York, Norton Library, 1972. ARnOLD, Denis. Monteverdi Madrigals. London, BBC Guides, 1978.

Bridgman, Nanie. La Musique a Venise. Paris, P.U.F., 1984.

Bukofzer, Manfred. La Musique Baroque. Paris, J.C. Lattès, 1988.

Burke, Peter. Veneza e Amsterdã - Um Estudo das Elites do Século XVII. São Paulo, Brasiliense, 1991.

Donington, Robert. The Rise of Opera. London, Faber \& Faber, 1981. Baroque Music - Style and Performance. London, Faber \& Faber, 1992.

FABBri, Paolo. Monteverdi. Torino, Edizioni di Torino, 1985.

FubInı, Enrico. La Estetica Musical del Siglo XVII a Nuestros Dias. Barcelona, Barral Editores, 1971.

Harnoncourt, Nikolaus. O Discurso dos Sons. Rio de Janeiro, Zahar, 1988.

Monteverdi, Claudio. Lettere, Dediche e Prefazioni. De' Paoli, Domenico (edizione critica e note). Roma, Edizioni de Santis, 1973.

Palisca, Claude. La Musica del Barroco. Buenos Aires, Editorial Victor Leru, 1978.

Roche, Maurice. Monteverdi. Paris, Solfèges/Seuil, 1960.

Tombinson, Gary. Monteverdi and the End of Renaissance. Berkeley, University of California Press, 1990. 